that form of this disease which is due to some abnormal condition of the digestive organs, and Dr. Macleod adopts it without any explanation. The former also says, "asthmatics are generally dyspeptics;" the latter points out that "asthmatics are generally more or less dyspeptic." According to Dr. Salter, the diet of the asthmatic " should be small in quantity, highly nourishing, and of easy digestion;" while Dr. Mlacleod believes that " the food of an asthmatic onght to be moderate in quantity, simple as regards cooking, and easy of digestion." A couple of columns might be filled with similar extracts; but sufficient has surely been noticed to prevent any non-professional person saying after this that doctors differ. Such charming unanimity has been seldom witnessed, we allow; and we are sure Dr. Salter must feel rather gratified to find that his views are so highly appreciated. Perhaps Dr. Macleod will urge that he has not attempted to be original; but surely this gentleman is not to be allowed to go on printing the writings of others without permission and without apology. In a previous work he has said- "We have never hesitated to use the words of others if they expressed fairly and with clearness our own views. We claim no originality for any thought or expression contained in the pages of this volume, our aim throughout being solely clearness and explicitness, with faithfulness of description." If such really be his object, it is a pity that he did not take one of our standard text-books, and reprint the chapters which suited his purpose-a proceeding that would have been attended with no trouble to himself, and which would certainly have been much more advantageous to his readers. Dr. Macleod, F.R.C.P., has doubtless heard that " of the making of books there is no end ;" but he seems to care not, so that he can get a few hypochondriacal old ladies to look upon him as a water prophet.

With regard to the four letters which this gentleman appends to his name, we have also a word or two to say. In our simplicity we supposed that they denoted the possession of the Fellowship of the Royal College of Physicians of London. According to the Medical Directory, however, not to mention the Medical Register, Dr. Macleod happens to be a Fellow of the Royal College of Physicians of Edinburgh.

And now, in conclusion, one or two remarks on the compressed air bath. This bath may be roughly compared to a diving-bell under water into which condensed air is forced by a steam-engine, due care of course being taken to keep the atmosphere pure. As Dr. Salter points out, if the pressure be that of two atmospheres, every cubic foot of air will contain the oxygen and nitrogen of two cubic feet at the ordinary pressure; and hence an asthmatic whose contracted bronchi only allow him to inhale half the usual amount of air, will, on breathing such a doubly oxygenated atmosphere, have the balance restored. Now it is not unreasonable to suppose that, if on the asthmatic awaking at midnight he could at once step into this bath, he might feel for the time almost or quite as easy under his attack as if he were free from it. But we require a great deal more evidence than Dr. Macleod has favoured us with before we can believe that this treatment will eradicate the disease-in other words, will prevent a return of the asthma. That this writer's statement must be received with great caution will be clear to anyone who carefully reads his pamphlet. But there is another reason for our scepticism. In 1857 an essayt was published recommending the treatment now so strongly advocated in asthma for the cure of consumption. Dr. Macleod condescended to write a preface to this paper, in which he says :-

"The reader of this essay upon the compressed air bath will probably be struck with the unhesitating manner in which

* The Treatment of Small-pox, Measles, Scarlet Fever, Hooping-cough, Croup, Quinsy, \&c, by the Water Cure and Homoopathy, Adapted for the use of Families. By Dr. William Macleod. Manchester, 1848.

+ Compressed Air as a Therapeutic Agent in the Treatment of Consumption, Asthma, Chronic Bronchitis, and other Diseases. By Archibald Simpson, M.D. Assistant-Physician to Ben Rhydding. With a Preface by William Macleod, MI.D. Edinburgh, 1857 .
Dr. Simpson writes of the general curability of consumption.... I can assure the reader, however, that the statements of Dr. Simpson in this paper are neither at all exaggerated nor the result of false diagnosis." The bath " causes the absorption of the tubercular matter deposited in the lungs."

We can only observe that, if this last statement be true, neither Dr. Simpson nor Dr. Macleod has yet received the reward he merits, and therefore the sooner their effigies ap. pear in Trafalgar-square or on Carlton-hill the better will it be for our national credit. There is but one unimportant question to be first answered, and it is this: If the physicians of Ben Rhydding can cure consumption, how is it that the Registrar-General's black book shows no diminution in the fearful mortality from this disease?

Obscure Diseases of the Brain and Disorders of the Mind. By Forbes Winsiow, M.D., D.C.L., \&c. Second Edition, revised. Octavo. pp. 720. London: John W. Davies.

WHEN the First Edition of Dr. Winslow's elaborate work appeared, we devoted considerable space to a review and analysis of its contents. That the Second Edition should be called for a very few months after the publication of the first is what might reasonably have been anticipated. In the present issue the work has been carefully revised, and many alterations and amendments have been made in it. The author has also incorporated a few extracts from his Lettsomian Lectures "On Insanity," which originally appeared in The Lavoet. Dr. Winslow's treatise has become the modern text-book on insanity.

British Wild Flowers. Illustrated hy JOHN E. SoweRBY, Illustrator of "The Ferns of Great Britain," "The Grasses of Great Britain," \&c. Described, with an Intruduction, and a Key to the Natural Orders, by C. Pierpornt JoHnson. London: John Van Voorst.

Mr. SowErsy has at length completed his elegant book on "British Wild Flowers," which will be found to be a volume of reference for the field botanist, the country resident, or the summer rambler. It contains illustrations of 1600 specimens, all faithful representations of nature, and beautifully coloured. Considering that every single specimen required to be individually portrayed by the hand of the artist, the book is a marvellous example of labour and cheapness, and cannot fail to obtain a large circulation.

\section{CONCEALED PREMATURE CHILDREN.} To the Editor of THE LANCET.

Sir,-Twice lately have I been called upon to advise as to the course to be adopted when the concealed fruit of premature labour has been discovered. Having felt much embarrassment on the point, I ask you to put upon record the facts.

About a year since, a foetus of six or seven months was discovered in a churchyard, enclosed in a fig-box. Mr. Humphreys thought an inquest unnecessary, and the body was disposed of through the workhouse authorities.

On the 16 th inst., a fotus of about six months was found poked into a drain; it was quite fresh, with the placenta attached, and was wrapped in a cloth. Mr. Ratcliffe thought it unnecessary to hold an inquest. I was asked to certify to my opinion that it could not have lived, and the body is to be disposed of in the same way as the former.

Doubtless such cases are often the result of criminal abortions, but when the foetuses are probably not viable, it is difficult to refuse certifying to that effect, though the practice of interring them in that way seems very questionable. I am, Sir, yours, \&c.,

Spital-square, June, 1861. JAMES EDMUNDs, L.R.C.P. Ed.

UNiversity CoLlege, London.-At a special session of Council, held on the 15th inst. (for the 16th of June, the anniversary appointed by the founder for the election to the Atkinson Morley Surgical Scholarship), the scholarship, £45 per annum, tenable for three years, was awarded to Mr. Henry Charlton Bastian, of Falmouth. 